\title{
Vagus Nerve Stimulation in Intractable Epilepsy
}

\author{
Cem BOLUK ${ }^{1}$, Cigdem OZKARA ${ }^{1}$, Cihan ISLER ${ }^{2}$, Mustafa UZAN² \\ ${ }^{1}$ Istanbul University-Cerrahpasa, Cerrahpasa Faculty of Medicine, Department of Neurology and Clinical Neurophysiology, Istanbul, Turkey \\ ${ }^{2}$ Istanbul University-Cerrahpasa, Cerrahpasa Faculty of Medicine, Department of Neurosurgery Istanbul, Turkey \\ This study has been presented at the $56^{\text {th }}$ National Neurology Congress between 28 November and 02 December 2020, turkey
}

Corresponding author: Cem BOLUK cem_boluk@hotmail.com

\section{ABSTRACT}

AIM: To investigate and compare the efficacy and safety of vagus nerve stimulation (VNS) therapy in different types of epilepsy.

MATERIAL and METHODS: Patients, who were implanted with VNS between the years 2005 and 2020, were retrospectively included in the study. Age, gender, age at seizure onset, epilepsy types, VNS implantation year, replacement year, pre and post-VNS seizure frequency, number of responders, number of antiseizure medication and adverse events were recorded.

RESULTS: In total, 41 patients were included in the study. The number of patients with focal epilepsy was 21 (51.2\%). 10 patients (24.4\%) had generalized epilepsy and 10 patients (24.4\%) had "combined generalized and focal epilepsy" (Lennox-Gastaut, Dravet syndrome). The Pre-VNS median seizure frequency was 1.5/day in the focal group, 0.6 /day in the generalized group and $6 /$ day in the combined group. Seizure frequencies dropped to 0.3 /day in the focal group, 0.2 /day in the generalized group and $3.0 /$ day in the combined group at the $12^{\text {th }}$ month after VNS $(p<0.001, p=0.004, p<0.001)$. The response rate was found to be $68.3 \%$ at the 12th month after VNS. The number of antiseizure medications was decreased from 3.6/day to 3.1/day at the 12th months after VNS $(p<0.001)$. Two patients' (4.9\%) VNS therapy was discontinued due to adverse events.

CONCLUSION: The study indicates that VNS therapy is safe and effective in focal, generalized and combined epilepsy types. Despite having a low seizure freedom rate, VNS is a good alternative treatment option for patients who for any reason are not candidates for resective surgery.

KEYWORDS: Efficacy, Epilepsy, Intractable, Seizure, Treatment, Vagus nerve stimulation

ABBREVIATIONS: SUDEP: Sudden unexpected death in epilepsy, VNS: Vagus nerve stimulation

\section{INTRODUCTION}

E pilepsy is a fairly common neurological disease that affects 7 out of 1000 people in the world (13). Additional problems such as psychiatric co-morbidity, stigmatization, caregivers' burnout, and high economic burden make it more difficult to manage $(5,12,15,31)$. Despite the availability of many antiseizure medication options, $20 \%-$ $30 \%$ of epilepsy cases are still intractable $(8,16,24,26)$. Some of these medically intractable patients may be eligible for resective surgery. However, managing seizures in the rest of those patients is still one of the most important problems for neurologists and epileptologists $(22,27)$.
Vagus nerve stimulation (VNS) is a well-known treatment option for focal and generalized epilepsy that has become an established approach in experienced centers $(6,20)$. Demonstrated efficacy in randomized control trials on medically intractable patients with focal epilepsy had established VNS as a favored method at the end of the 1990s. It has since continued to show benefits in reducing seizure frequency in open-label studies $(6,14,17,19)$. Although VNS is undoubtedly superior to a placebo, studies have shown that the rate of patients who are completely seizure-free remains at $0 \%-13 \%(2,11,18)$. In addition, the reported responder rates from different studies vary widely $(2,3,11,17-19)$.
Cem BOLUK (D): 0000-0003-0125-7660

Cigdem OZKARA (1) : 0000-0003-0548-1838
Cihan ISLER (1) : 0000-0001-8365-3338

Mustafa UZAN (D) : 0000-0001-7214-380X 
This study describes the experience at our center with VNS in patients with intractable epilepsy.

\section{- MATERIAL and METHODS}

This study was approved by the local ethics committee. The approval number is 06/11/2020-146358.

This study was designed as a retrospective observational study. The STROBE guidelines were followed during the course of the research (32). Patients treated with VNS between 2005 (the first implantation year in our center) and 2020 were included in the study. Patients' age, sex, age at onset of seizures, type of epilepsy, epilepsy syndrome (if any), seizure frequency before VNS, the number of antiseizure medications before VNS, implantation year, seizure frequency after VNS, number of antiseizure medications after VNS, output currency, adverse events, date of battery change (if applicable), and the subjective evaluation of patients and their caregivers were recorded.

Seizure type, epilepsy type, and epilepsy syndromes were defined according to the new International League Against Epilepsy 2017 classification (25). Seizure diaries were used to determine seizure frequencies.

The efficacy of VNS therapy was assessed in three different ways at three different times. The first parameter was the decrease in the median number of seizure frequency at the $6^{\text {th }}, 12^{\text {th }}$, and $18^{\text {th }}$ months after VNS implantation. Secondly, the number of "responders" was determined using the $\geq 50 \%$ seizure reduction criterion after 6,12 , and 18 months from VNS implantation. Lastly, the subjective evaluation of patients and their caregivers were collected through forms they accomplished regarding the percentage of benefit at the $12^{\text {th }}$ month after VNS implantation. Our standard initial stimulation parameter (output current) was $0.25 \mathrm{~mA}$. The output current was increased stepwise during the monthly follow-ups.

\section{Inclusion Criteria}

Patients who were implanted with VNS at Istanbul UniversityCerrahpaşa between the years 2005 and 2020 were included in the study.

\section{Exclusion Criteria}

Patient who lack data in their medical records and who did not have follow-ups were excluded.

\section{Statistical Analyses}

SPSS version 21.0 (SPSS Inc., Chicago, IL, USA) was used for the calculation of frequency distributions and percentages. The t-test was used to perform comparisons. The Wilcoxon test was used to analyze data that were not normally distributed. The one-way analysis of variance test was used for variance analysis. The Kruskal-Wallis test was used when the variances were unequal. The Friedman test was used to analyze time-dependent changes. Finally, the Bonferroni correction was applied for multiple comparisons.

\section{RESULTS}

Patient demographic and clinical characteristics are summarized in Table I. After the exclusion of 3 patients due to lack of data and follow-ups, 41 patients were ultimately included in the study. The male/female ratio was $1.7(26 / 15)$. The mean age of patients was $29.5 \pm 9.5$ years. Twenty-one patients $(51.2 \%)$ were diagnosed with focal epilepsy, 10 patients $(24.4 \%)$ with generalized epilepsy, and 10 patients (24.4\%) with combined generalized and focal epilepsy (Lennox-Gastaut and Dravet syndrome). Five patients (12.2\%) had a prior history of unsuccessful resective epilepsy surgery. The mean age at seizure onset was $6.4 \pm 6.2$ years (range: 0-29) in all patients. Age at seizure onset was statistically low in the combined group when compared with the focal or generalized groups $(p=0.029)$ (Table I). The mean age at VNS implantation was $21.9 \pm 10.6$ years (range: $4-50$ ). Mean age at VNS implantation was low in the combined group but not statistically significant when compared with the other groups $(p=0.082)$ (Table I). The mean follow-up period after implantation was $65.4 \pm 36.5$ months.

\section{Pre-VNS Data}

The preoperative median seizure frequency was $2 /$ day in all groups. The median seizure frequency in the combined group (6/day) was significantly higher than in the other groups $(p=0.013)$. Median seizure frequency was $1.5 /$ day in the

Table I: Pre-VNS Clinical and Demographic Characteristics of the Patients

\begin{tabular}{|c|c|c|c|c|}
\hline & Focal Group & Generalized Group & Combined Group & $\mathbf{p}$ \\
\hline $\mathrm{M} / \mathrm{F}$ ratio & 2 & 1 & 2.3 & 0.271 \\
\hline Mean age, y & $29.9 \pm 9.8$ & $31.0 \pm 9.4$ & $25.2 \pm 4.5$ & 0.239 \\
\hline Mean age at seizure onset, y & $6.7 \pm 5.3$ & $8.5 \pm 4.9$ & $2.6 \pm 3.5$ & 0.026 \\
\hline Mean time from the diagnosis to VNS implantation, y & $15.7 \pm 8.7$ & $16.6 \pm 9.1$ & $12.9 \pm 6.6$ & 0.579 \\
\hline Pre-VNS median seizure frequency per day & 1.5 & 0.6 & 6.0 & 0.013 \\
\hline Pre-VNS mean number of antiseizure medication & $3.5 \pm 0.6$ & $3.6 \pm 0.5$ & $3.6 \pm 0.7$ & 0.923 \\
\hline
\end{tabular}


focal group and $0.6 /$ day in the generalized group. The mean number of pre-VNS antiseizure medications was $3.6 \pm 0.6$ and no significant differences were observed among the 3 groups $(p=0.950)$.

\section{After VNS Implantation}

The median seizure frequencies of all patients at the $6^{\text {th }}, 12^{\text {th }}$, and $18^{\text {th }}$ months after VNS implantation were 0.9/day, 0.4/day, and $0.2 /$ day respectively. All differences were significant when compared with the pre-VNS frequencies $(2 /$ day; $\mathrm{p}<0.001)$. However, the decrease in frequency was significant at the $12^{\text {th }}$ month. No statistically significant differences were observed between the $12^{\text {th }}$ and $18^{\text {th }}$ months after implantation $(p=0.360)$.

In the focal group, the median seizure frequency at the $6^{\text {th }}, 12^{\text {th }}$, and $18^{\text {th }}$ months after VNS implantation, were $0.5 /$ day, $0.3 /$ day, and $0.1 /$ day, respectively. All differences were significant when compared with the preoperative data (1.5/day; $p<0.001)$. The downward trend in frequency was significant until the end of the $18^{\text {th }}$ month $(p<0.001, p=0.006$, and $p=0.021$, respectively).

In the generalized group, the median seizure frequency at the $6^{\text {th }}, 12^{\text {th }}$, and $18^{\text {th }}$ months after VNS implantation were $0.1 /$ day, 0.2/day, and 0.2/day, respectively. All differences were significant when compared with the preoperative ata $(0.6 /$ day; $\mathrm{p}=0.004)$. However, no significant difference was observed after the $6^{\text {th }}$ month $(\mathrm{p}=0.018,0.484$, and 0.624 , respectively).

In the combined group, the median seizure frequency at the $6^{\text {th }}, 12^{\text {th }}$, and $18^{\text {th }}$ months after VNS implantation were $4 /$ day, $3 /$ day, and 1/day, respectively. All differences were significant when compared with the preoperative data $(6 /$ day; $p<0.001)$. The downward trend in frequency was significant at the $6^{\text {th }}$ and $12^{\text {th }}$ months ( $p=0.007$ and 0.042 , respectively). No significant difference was observed between the $12^{\text {th }}$ and $18^{\text {th }}$ months after implantation $(p=0.109)$.

\section{Number of Responders ( $\geq 50 \%$ Reduction in Seizure Frequency)}

The number of responders steadily increased during the observation period, with $22(53.7 \%)$ at the $6^{\text {th }}$ month after VNS implantation, $28(68.3 \%)$ at the $12^{\text {th }}$ month, and 31 $(75.6 \%)$ at the $18^{\text {th }}$ month. The number of patients with $\geq 75 \%$ reduction in seizure frequency was $20(48.8 \%)$ at the end of follow-up. Only 2 patients (4.9\%) were seizure-free after VNS implantation. One patient $(2.4 \%)$ discontinued therapy due to ineffectiveness. Furthermore, the response rate increased with time in the focal group but remained unchanged in the generalized and combined groups after 6 months. The response rates according to epilepsy type and time are shown in Table II and Figure 1.

\section{Subjective Evaluation}

The mean reported benefit ratio of all three groups according to the subjective evaluation of patients and their caregivers was $40.5 \%$ at the $12^{\text {th }}$ month. Per group, the mean reported benefit ratio was $37 \%$ in the focal group, $46 \%$ in the generalized group, and $46 \%$ in the combined group. These ratios were not statistically different from one another $(p=0.762)$.

\section{Antiseizure Medications}

The mean number of antiseizure medications in the pre-VNS period was $3.6 \pm 0.6$, which dropped to $3.2 \pm 0.7$ at the $12^{\text {th }}$ month $(p=0.001)$ in all groups. In the subgroup analyses, the reduction in the number of antiseizure medications was significant except in the combined group $(p=0.50,0.025$, and 0.104 , respectively) (Table III).

\section{Adverse Events}

Fifteen out of 41 patients (36.6\%) reported at least one adverse event up until the end of the follow-up period. The most common side effects were cough $(n=5 ; 12.2 \%)$,

Table II: Number of Responders in Different Groups by Time After VNS Implantation

\begin{tabular}{lccc}
\hline & $\mathbf{6}^{\text {th }}$ month & 12 $^{\text {th }}$ month & $\mathbf{1 8}^{\text {th }}$ month \\
\hline Focal group & $52.4 \%(11 / 21)$ & $71.4 \%(15 / 21)$ & $85.7 \%(18 / 21)$ \\
\hline Generalized group & $50 \%(5 / 10)$ & $50 \%(5 / 10)$ & $50 \%(5 / 10)$ \\
\hline Combined group & $60 \%(6 / 10)$ & $80 \%(8 / 10)$ & $80 \%(8 / 10)$ \\
\hline
\end{tabular}

Table III: Pre-VNS and Post-VNS Data Comparison

\begin{tabular}{|c|c|c|c|c|c|c|c|c|}
\hline & $\begin{array}{l}\text { Pre-VNS } \\
\text { median } \\
\text { seizure } \\
\text { frequency } \\
\text { (/day) }\end{array}$ & $\begin{array}{l}6^{\text {th }} \text { month } \\
\text { median } \\
\text { seizure } \\
\text { frequency } \\
\text { (/day) }\end{array}$ & $\begin{array}{l}1^{\text {th }} \text { month } \\
\text { median } \\
\text { seizure } \\
\text { frequency } \\
\text { (/day) }\end{array}$ & $\begin{array}{l}\text { 18 }^{\text {th }} \text { month } \\
\text { median } \\
\text { seizure } \\
\text { frequency } \\
\text { (/day) }\end{array}$ & $\mathbf{p}$ & $\begin{array}{c}\text { Pre-VNS } \\
\text { mean ASM } \\
\text { (n) }\end{array}$ & $\begin{array}{c}\text { Post-VNS } \\
\text { mean ASM } \\
\text { (n) }\end{array}$ & $\mathbf{p}$ \\
\hline Focal Group & 1.5 & 0.5 & 0.3 & 0.1 & $<0.001$ & $3.5 \pm 0.6$ & $3.2 \pm 0.5$ & 0.050 \\
\hline Generalized Group & 0.6 & 0.1 & 0.2 & 0.2 & 0.004 & $3.6 \pm 0.5$ & $2.9 \pm 0.9$ & 0.025 \\
\hline Combined Group & 6.0 & 4.0 & 3.0 & 1.0 & $<0.001$ & $3.6 \pm 0.7$ & $3.2 \pm 0.8$ & 0.104 \\
\hline
\end{tabular}

VNS: Vagus nerve stimulation, ASM: Antiseizure medication. 


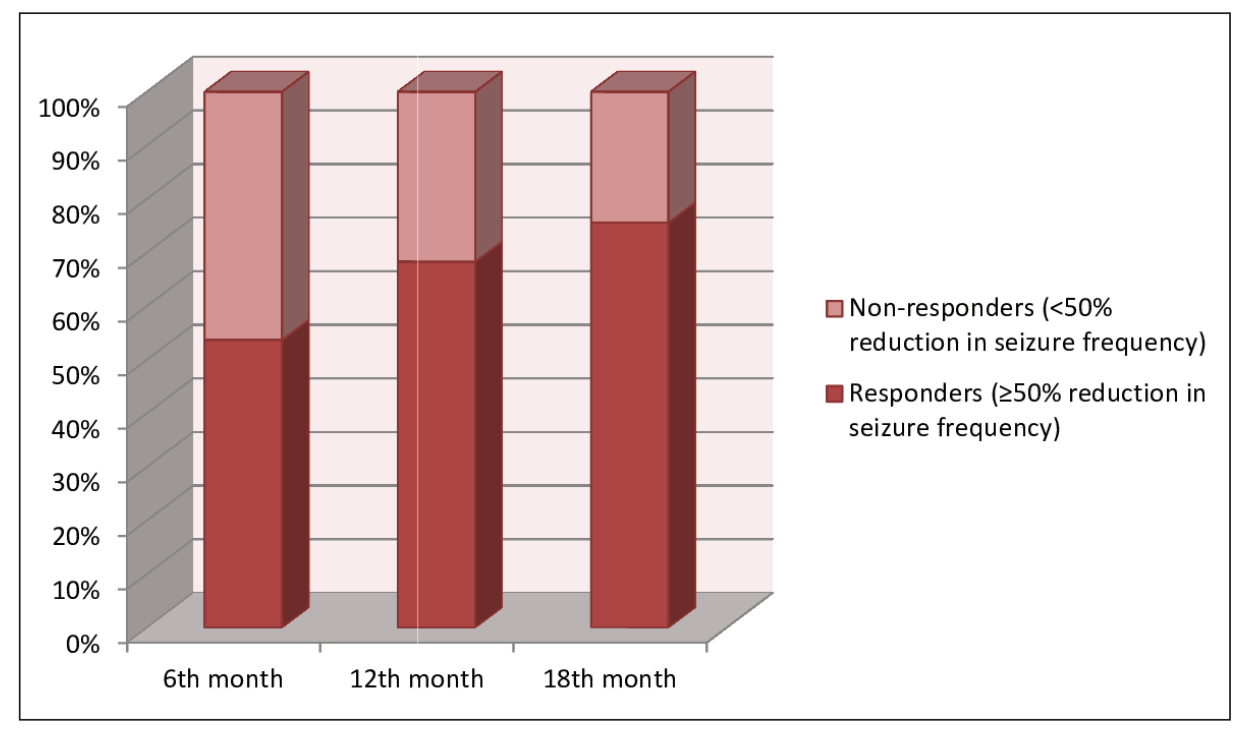

Figure 1: Response rates after VNS implantation. hoarseness $(n=4 ; 9.8 \%)$, nausea $(n=3 ; 7.3 \%)$, fatigue $(n=2$; $4.9 \%)$, and infection $(n=1 ; 2.4 \%)$. The output current could not be increased from $0.50 \mathrm{~mA}$ due to adverse events in one patient, but the patient wanted to continue VNS therapy at this output adjustment. Two patients (4.9\%) discontinued VNS therapy due to adverse events. One patient $(2.4 \%)$ who had achieved seizure freedom died of sudden unexpected death in epilepsy (SUDEP) after 18 months. One patient became pregnant during VNS therapy. Delivery occurred at 39 weeks via cesarean section without any complications. The baby was healthy and has developed normally without any malformations presented.

\section{Stimulation Parameters and Battery Life}

At the last visit after VNS implantation, the mean output current was $1.9 \pm 0.4 \mathrm{~mA}$ (range: $0.50-2.75$ ), the mean frequency was $28.9 \pm 3.2 \mathrm{~Hz}$, and the mean pulse width was $426.8 \pm 121.4 \mu \mathrm{s}$. The average duty cycle had been set at 32.4 \pm 14.8 seconds for on-time and $3.62 \pm 2.45$ minutes for offtime. Battery depletion was observed in 22 patients during the follow-up period, and batteries were changed in 20 patients. The mean battery life was found to be $5.9 \pm 2.1$ years (range: 3-12 years).

\section{DISCUSSION}

This study showed that VNS therapy is effective in controlling seizures regardless of epilepsy type. Seizure frequency and the mean number of antiseizure medications significantly decreased after VNS implantation. Responder rates were satisfactory and reached the maximum level (75.6\%) at the $18^{\text {th }}$ month, demonstrating the time-dependent effect of VNS. The subjective self-reported benefit ratio was also satisfactory. Adverse events were well tolerated, and only two patients needed the device removed. The discontinuation ratio due to side effects was $4.9 \%$.

In a recent retrospective study investigating the efficacy of VNS in 11 patients with primary generalized epilepsy, 64\% of patients reported a reduction in seizure frequency (33). However, a $50 \%$ limit was not used in reporting the decrease in seizure frequency. Additionally, unlike our study, VNS showed no significant effect on antiseizure medications.

In another study which consisted of 24 patients with focal epilepsy, the median seizure frequency decreased from 16.5/ month to $8.5 /$ month at the $12^{\text {th }}$ month after VNS, dropping even further to $5 /$ month on long-term follow-up. The percentage of patients reporting a decrease in seizure frequency was $69.2 \%$, while $30.8 \%$ of patients reported no change (29). No significant difference was observed in the number of antiseizure medications after VNS.

Alexopoulos et al. showed that in a pediatric age group, $58.7 \%$ of patients showed $\geq 50 \%$ reduction, whereas $43.5 \%$ of patients showed $\geq 75 \%$ reduction in seizure frequency after VNS. They did not find any effect of VNS on the number of antiseizure medications. Furthermore, three patients died during the follow-up period, two of which probably died from SUDEP and one patient from surgical complications not related to VNS. The reported adverse events rate was $56 \%$, and the discontinuation rate due to adverse events or inefficacy was $21.7 \%$ (1). In our series, the discontinuation rate was considerably lower at $9.7 \%(n=4 ; 1$ died, 2 adverse events, and 1 inefficacy).

In our cohort, one patient became pregnant during VNS therapy and delivered a full-term healthy baby without complications or malformations. The literature has shown that VNS is not related to teratogenicity, and the risk of congenital malformations is low $(23,30)$. However, increased obstetric interventions (cesarean sections, vacuum extractions, etc.) have been observed in patients treated with VNS (23). Another pediatric study with 38 patients, reported that $68 \%$ of patients showed $\geq 50 \%$ reduction in seizure frequency at the $12^{\text {th }}$ month after VNS (21), which is almost the same as our study findings.

In one of the broadest studies to date consisting of 189 patients, the male/female ratio was 1.2 , compared with 1.7 
in our study. The mean age at VNS implantation was much higher than that in our study (30 years vs 21.9 years), but the mean output currents at the last visit were similar $(1.6 \mathrm{~mA}$ vs $1.9 \mathrm{~mA}$ ). However, the study used the Engel classification to evaluate efficacy instead of 50\% reduction (34). In a Canadian study that included 30 patients, the response rates were found to be lower at the $6^{\text {th }}$ and the $12^{\text {th }}$ months $(43 \%$ and $48 \%$, respectively) when compared with our study $(53.7 \%$ and $68.3 \%$, respectively). However, the adverse events rate and types of adverse events were very similar. Ten percent of patients reported dysphonia, $10 \%$ hoarseness, $7 \%$ cough, and $3 \%$ dysphagia (2). The main reason for our higher response rate may be due to the higher pre-VNS seizure frequencies in our cohort.

In our study, the mean age at seizure onset in the combined group was found to be significantly lower when compared with the other groups. Additionally, the pre-VNS seizure frequency was much higher in the combined group. The Dravet and Lennox-Gastaut syndromes are well-known severe forms of epilepsy that manifest in childhood and are associated with frequent seizures and different seizure types $(4,10)$.

Although the reduction in the median seizure frequency was significant and the response rates were relatively high (68.3\%), the reported subjective-benefit ratio remained low (40.5\%) at the $12^{\text {th }}$ month. One reason could be the high expectations of patients and caregivers regarding VNS implantation. Despite full information being given and risks and expectations being presented at preoperative informed consent, seizure freedom was probably the most desired result for both patients and caregivers. However, it could not be achieved for most patients.

Reported battery life varies widely and is dependent on battery models and device stimulation settings (output currents, duty cycle, etc.) $(7,9,28)$. In this study, the mean battery life was found to be 5.9 years which is consistent with the literature.

\section{Limitations of the Study}

Our study has several limitations. The main limitation is that it was a retrospective study. The second limitation is having a relatively small sample size obtained from a single center. In addition, stimulation parameters were not compared among the three groups. Some epilepsy syndromes and seizures are known to evolve with time. However, other than the response rate to VNS, the pure effect of time on some symptoms was not considered. Last but not least, this study did not investigate the effect of VNS on seizure severity and quality of life.

\section{CONCLUSION}

By this study, we confirmed that VNS therapy is safe and effective in focal, generalized and combined epilepsy types. Despite having a low seizure freedom rate, VNS seems to be an important treatment option for patients who for any reason are not candidates for resective surgery.

\section{REFERENCES}

1. Alexopoulos AV, Kotagal P, Loddenkemper T, Hammel J, Bingaman WE: Long-term results with vagus nerve stimulation in children with pharmacoresistant epilepsy. Seizure 15(7):491503, 2006

2. Arcand J, Waterhouse K, Hernandez-Ronquillo L, Vitali A, Tellez-Zenteno JF: Efficacy of vagal nerve stimulation for drug-resistant epilepsy: Is it the stimulation or medication?. Can J Neurol Sci 44(5):532-537, 2017

3. Arhan E, Serdaroglu A, Kurt G, Bilir E, Durdag E, Erdem A, Aksakal FN, Ozcelik A, Baykaner K: The efficacy of vagal nerve stimulation in children with pharmacoresistant epilepsy: Practical experience at a Turkish tertiary referral center. Eur $\mathrm{J}$ Paediatr Neurol 14(4):334-339, 2010

4. Arzimanoglou A, French J, Blume WT, Cross JH, Ernst JP, Feucht M, Genton P, Guerrini R, Kluger G, Pellock JM, Perucca E, Wheless JW: Lennox-Gastaut syndrome: A consensus approach on diagnosis, assessment, management, and trial methodology. Lancet Neurol 8(1):82-93, 2009

5. Begley CE, Beghi E: The economic cost of epilepsy: A review of the literature. Epilepsia 43 Suppl 4:3-9, 2002

6. Ben-Menachem E, Mañon-Espaillat R, Ristanovic R, Wilder BJ, Stefan H, Mirza W, Tarver WB, Wernicke JF: Vagus nerve stimulation for treatment of partial seizures: 1. A controlled study of effect on seizures. First international vagus nerve stimulation study group. Epilepsia 35:616-626, 1994

7. Bodin E, Le Moing AG, Bourel-Ponchel E, Querne L, Toussaint $P$, Berquin $P$ : Vagus nerve stimulation in the treatment of drug-resistant epilepsy in 29 children. Eur J Paediatr Neurol 20(3):346-351, 2016

8. Brodie MJ, Dichter MA: Antiepileptic drugs. N Engl J Med 334(3):168-175, 1996

9. Ching J, Khan S, White P, Reed J, Ramnarine D, Sieradzan K, Sandeman D: Long-term effectiveness and tolerability of vagal nerve stimulation in adults with intractable epilepsy: A retrospective analysis of 100 patients. $\mathrm{Br} \mathrm{J}$ Neurosurg 27(2):228-234, 2013

10. Dravet C: Dravet syndrome history. Dev Med Child Neurol 53 Suppl 2:1-6, 2011

11. Englot DJ, Rolston JD, Wright CW, Hassnain KH, Chang EF: Rates and predictors of seizure freedom with vagus nerve stimulation for intractable epilepsy. Neurosurgery 79(3):345-353, 2016

12. Fiest KM, Birbeck GL, Jacoby A, Jette N: Stigma in epilepsy. Curr Neurol Neurosci Rep 14:444, 2014

13. Fiest KM, Sauro KM, Wiebe S, Patten SB, Kwon CS, Dykeman $\mathrm{J}$, Pringsheim T, Lorenzetti DL, Jetté N: Prevalence and incidence of epilepsy: A systematic review and meta-analysis of international studies. Neurology 88(3):296-303, 2017

14. Handforth A, DeGiorgio CM, Schachter SC, Uthman BM, Naritoku DK, Tecoma ES, Henry TR, Collins SD, Vaughn BV, Gilmartin RC, Labar DR, Morris GL 3rd, Salinsky MC, Osorio I, Ristanovic RK, Labiner DM, Jones JC, Murphy JV, Ney GC, Wheless JW: Vagus nerve stimulation therapy for partial-onset seizures: A randomized active- control trial. Neurology 51:4855,1998 
15. Hansen B, Szaflarski M, Bebin EM, Szaflarski JP: Affiliate stigma and caregiver burden in intractable epilepsy. Epilepsy Behav 85:1-6, 2018

16. Hitiris N, Mohanraj R, Norrie J, Sills GJ, Brodie MJ: Predictors of pharmacoresistant epilepsy. Epilepsy Res 75(2-3):192-196, 2007

17. Holmes MD, Silbergeld DL, Drouhard D, Wilensky AJ, Ojemann LM: Effect of vagus nerve stimulation on adults with pharmacoresistant generalized epilepsy syndromes. Seizure 13:340-345, 2004

18. Janszky J, Hoppe M, Behne F, Tuxhorn I, Pannek HW, Ebner A: Vagus nerve stimulation: Predictors of seizure freedom. $J$ Neurol Neurosurg Psychiatry 76(3):384-389, 2005

19. Kawai K, Tanaka T, Baba H, Bunker M, Ikeda A, Inoue $Y$, Kameyama S, Kaneko S, Kato A, Nozawa T, Maruoka E, Osawa M, Otsuki T, Tsuji S, Watanabe E, Yamamoto T: Outcome of vagus nerve stimulation for drug-resistant epilepsy: The first three years of a prospective Japanese registry. Epileptic Disord 19:327-338, 2017

20. Labar D, Nikolov B, Tarver B, Fraser R: Vagus nerve stimulation for symptomatic generalized epilepsy: A pilot study. Epilepsia 39:201-205, 1998

21. Patwardhan RV, Stong B, Bebin EM, Mathisen J, Grabb PA: Efficacy of vagal nerve stimulation in children with medically refractory epilepsy. Neurosurgery 47(6):1353-1358, 2000

22. Ramey WL, Martirosyan NL, Lieu CM, Hasham HA, Lemole GM Jr, Weinand ME: Current management and surgical outcomes of medically intractable epilepsy. Clin Neurol Neurosurg 115(12):2411-2418, 2013

23. Sabers A, Battino D, Bonizzoni E, Craig J, Lindhout D, Perucca E, Thomas SV, Tomson T, Vajda F: Maternal and fetal outcomes associated with vagus nerve stimulation during pregnancy. Epilepsy Res 137:159-162, 2017

24. Sander JWAS: Some aspects of prognosis in the epilepsies: $A$ review. Epilepsia 34:1007-1016, 1993
25. Scheffer IE, Berkovic S, Capovilla G, Connolly MB, French J, Guilhoto L, Hirsch E, Jain S, Mathern GW, Moshé SL, Nordli DR, Perucca E, Tomson T, Wiebe S, Zhang YH, Zuberi SM: ILAE classification of the epilepsies: Position paper of the ILAE commission for classification and terminology. Epilepsia 58(4):512-521, 2017

26. Schmidt D, Gram L: Monotherapy versus polytherapy in epilepsy: A reappraisal. CNS Drugs 3:194-208, 1995

27. Schuele SU, Lüders HO: Intractable epilepsy: Management and therapeutic alternatives. Lancet Neurol 7(6):514-524, 2008

28. Smyth MD, Tubbs RS, Bebin EM, Grabb PA, Blount JP: Complications of chronic vagus nerve stimulation for epilepsy in children. J Neurosurg 99(3):500-503, 2003

29. Spanaki MV, Allen LS, Mueller WM, Morris GL 3rd: Vagus nerve stimulation therapy: 5-year or greater outcome at a university-based epilepsy center. Seizure 13(8):587-590, 2004

30. Suller Marti A, Mirsattari SM, Steven DA, Parrent AG, MacDougall KW, McLachlan RS, Burneo JG: Experience on the use of Vagus Nerve Stimulation during pregnancy. Epilepsy Res 156:106186, 2019

31. Tellez-Zenteno JF, Patten SB, Jetté N, Williams J, Wiebe S: Psychiatric comorbidity in epilepsy: A population-based analysis. Epilepsia 48:2336-2344, 2007

32. von Elm E, Altman DG, Egger M, Pocock SJ, Gøtzsche PC, Vandenbroucke JP; STROBE Initiative: The strengthening the reporting of observational studies in epidemiology (STROBE) statement: Guidelines for reporting observational studies. PLoS Med 4(10):e296, 2007

33. Welch WP, Sitwat B, Sogawa Y: Use of vagus nerve stimulator on children with primary generalized epilepsy. J Child Neurol 33(7):449-452, 2018

34. Wheeler M, De Herdt V, Vonck K, Gilbert K, Manem S, Mackenzie T, Jobst B, Roberts D, Williamson P, Van Roost $D$, Boon P, Thadani V: Efficacy of vagus nerve stimulation for refractory epilepsy among patient subgroups: A re-analysis using the Engel classification. Seizure 20(4):331-335, 2011 